\title{
STRUCTURAL REORGANIZATION OF THE RATS' SUBMANDIBULAR GLANDS ACINI AFTER THE INFLUENCE OF 1\% METHACRYLATE
}

D0I: 10.36740/WLek202007102

\author{
Galyna A. Yeroshenko ${ }^{1}$, Larysa Ya. Fedoniuk ${ }^{2}$, Konstantyn V. Shevchenko ${ }^{1}$, Denys R. Kramarenko ${ }^{1}$, \\ Anastasiia I. Yachmin ${ }^{1}$, Olena V. Vilkhova' ${ }^{1}$, Tetiana A. Skotarenko' \\ 'UKRAINIAN MEDICAL STOMATOLOGICAL ACADEMY, POLTAVA, UKRAINE \\ 2. HORBACHEVSKY TERNOPIL NATIONAL MEDICAL UNIVERSITY, TERNOPIL, UKRAINE
}

\begin{abstract}
Introduction: Polymeric substances, which are used in medicine, can lead to the development of pathological conditions. Therefore, in toxicological evaluation of polymeric materials for medical purposes the primary task is the creation of the appropriate adequate methods of study.

The aim: To study the acini of the rats'submandibular salivary glands in normal condition and after exposure of $1 \%$ methacrylate.

Material and methods: Were studied 50 white rats during the influence of $1 \%$ methacrylate on the mucosa of the oral cavity. Histological sections of the rats's submandibular salivary glands in normal condition, on day 14 and 30 of experiment were studied using the UMPT - 7 ultramicrotome of Sumy PA "Selmi".

Results and conclusions: The morphometric study has established that in control group the values of the outer diameter of the submandibular glands' acini, the diameter of the lumen and the height of the acini epithelial cells was $36,27 \pm 2,17 \mu \mathrm{m}, 9,47 \pm 0,63 \mu \mathrm{m}$ and $14,18 \pm 1,05 \mu \mathrm{m}$, respectively. Histological specimens showed that the acini cells had a prominent basophilia of the cytoplasm and the basally located nucleus. Numerous large homogeneous granules were located in the apical pole of the cells. After influence of the $1 \%$ methacrylat there is an increase in the activity of secretory cells, which is confirmed by an increase in the height of epitheliocytes by $25.04 \%$ and is a compensatory metacrylate reaction. The increase in salivation further leads to complete depletion of the secretory apparatus of the seromucosal cells, which is confirmed by a decrease in the outer and inner diameters with a decrease in the height of the mandibular salivary glands acini cells by $24.40 \%$.
\end{abstract}

KEY WORDS: salivary glands, rats, acini, epithelial cells, 1\% methacrylate

Wiad Lek. 2020;73(7):1318-1322

\section{INTRODUCTION}

Polymeric materials and substances, that migrate from polymeric materials, are used in medicine, and they can lead to the development of various pathological conditions. Therefore, in toxicological evaluation of polymeric materials for medical purposes the primary task is the creation of the appropriate adequate methods of study, which include the analysis of such factors as the nature and duration of contact of the polymeric product with the human body [1]. However, despite the disadvantages, methacrylates have been widely used in dentistry, as the base of dentures, due to their general using $[2,3]$. The toxic effect can be caused by the methyl ester of methacrylic acid. However, its toxic properties appear only at high doses [4]. Many scientific articles are devoted to the study of the effect of methacrylate monomer on the mucosa of the oral cavity $[5,6]$, though few of them are devoted to the study of the state of organs located outside the oral cavity after exposure to methacrylic acid.

It has been proved by evidence that patients, who wear dentures, often complaints of xerostomia. In this case, the major salivary glands must compensatory increase secretion to provide adequate moistening of the oral cavity mucosa [7]. The major salivary glands are composed of the secretory acini and the system of excretory ducts $[8,9]$. They consist of various glandular cells that are programmed to synthesize completely different products of secretion $[10,11]$. Investigating the histochemical characteristics of the structure of the acinar unit of the human major salivary glands, the researchers have found that the acinar units of the salivary glands are represented by two differentiated types of the secretory cells. The specificity of their differentiation is manifested by the secretion of mucus and protein $[12,13]$, which is crucial for the qualitative composition of saliva, which, subsequently, will affect the condition of the human oral cavity, dental and somatic health in general; therefore, studies in this field are of great practical importance $[14,15]$.

\section{THE AIM}

To determine the changes in the structural elements of the acini of the rats' submandibular salivary glands in normal condition and after exposure of $1 \%$ methacrylate.

\section{MATERIALS AND METHODS}

Were studied white male rats $(n=50$; controls: $n=10$; experimental animals: $n=40$ ). The mucosa of the oral cavity of rats was exposed by $1 \%$ methacrylate for 30 days [5]. The animals were killed on day 14 and 30 . The fragments of submandib- 
Table 1. The dynamics of the changes of morphomretric parameters of the acini of the submandibular glands (in $\mu \mathrm{m}$ )

\begin{tabular}{cccc}
\hline Acini & The outer diameter & $\begin{array}{c}\text { The diameter } \\
\text { of the lumen }\end{array}$ & $\begin{array}{c}\text { The height } \\
\text { of the epithelial cells }\end{array}$ \\
\hline Control group $(n=5)$ & $36,27 \pm 2,17$ & $9,47 \pm 0,63$ & $14,18 \pm 1,05$ \\
\hline Day14 $(n=5)$ & $37,33 \pm 2,96$ & $8,83 \pm 0,72$ & $17,73 \pm 1,11 *$ \\
\hline Day $30(n=5)$ & $28,99 \pm 2,14 * / * *$ & $7,89 \pm 0,82 *$ & $10,72 \pm 0,98 * / * *$ \\
\hline
\end{tabular}

Note: ${ }^{*}-\mathrm{P}<0,05$ compared with control group;

** $-\mathrm{P}<0,05$ compared with previous period of experiment.

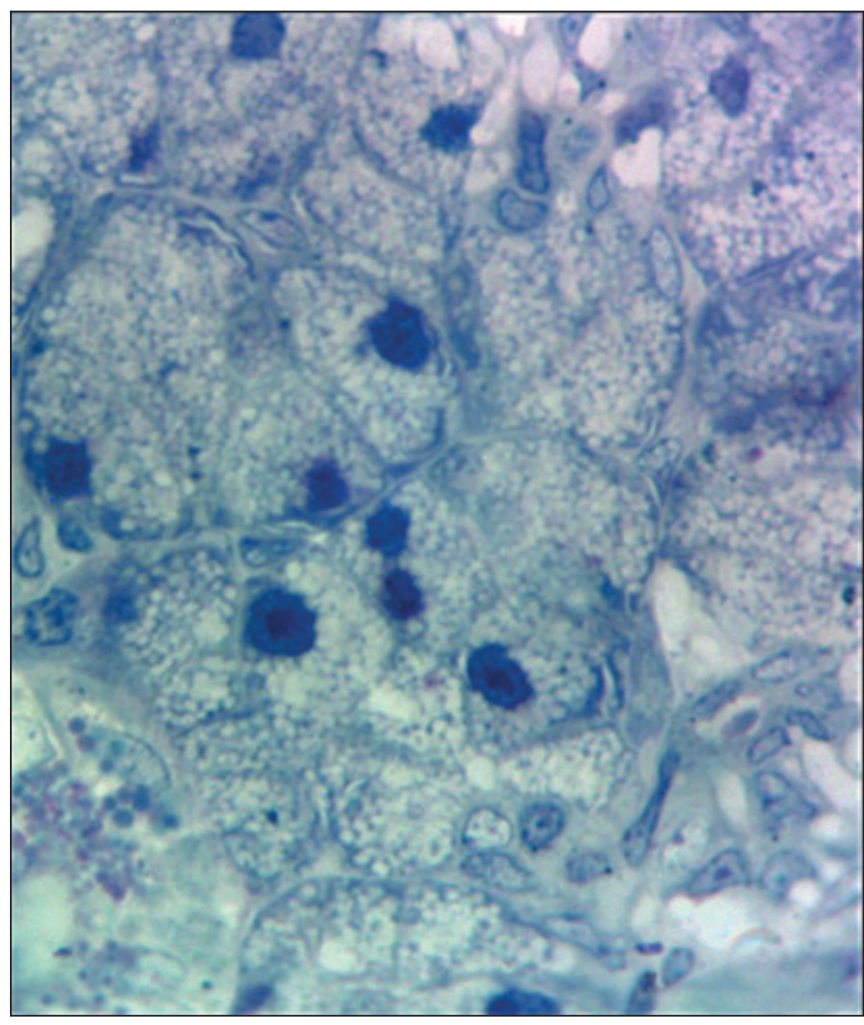

Fig. 1. Acini of the rats' submandibular gland on day 14 after the effect of $1 \%$ methacrylate.

Specimen. Polychrome staining. x1000.

ular glands were embedded into epon-812 [16]. Histological sections were made using the UMPT - 7 ultramicrotome of Sumy PA "Selmi" and stained with methylene blue and polychrome stain [17]. Morphometric study was doing by the Biorex-3 BM-500T microscope with digital DCM 900 microphoto-head with software, adapted to these studies. Conventional statistical methods have been used for statistical processing of the morphometric data and quantitative analysis by Microsoft Excel software [18].

Experiments have been carried out in compliance with the requirements of international principles of the "European Convention for the Protection of Vertebrate Animals Used for Experimental and Other Scientific Purposes" [19].

\section{RESULTS AND DISCUSSION}

The morphometric study [20] has established that in rats of control group the values of the outer diameter

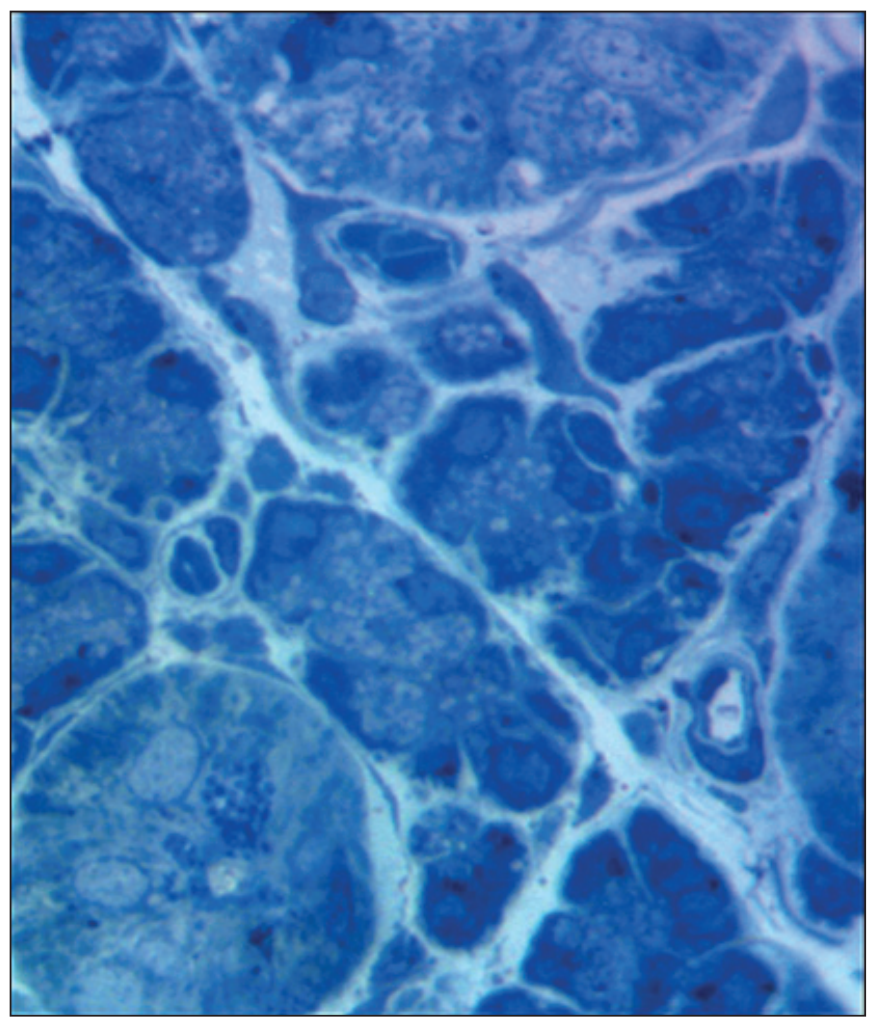

Fig. 2. Lobules of the rats' submandibular glands on day 30 of the experiment after the effect of $1 \%$ methacrylate. Specimen. Stained with Methylene blue. $x 1000$.

of the acini of the submandibular glands, the diameter of the lumen and the height of the acini epithelial cells was $36,27 \pm 2,17 \mu \mathrm{m}, 9,47 \pm 0,63 \mu \mathrm{m}$ and $14,18 \pm 1,05 \mu \mathrm{m}$, respectively (Table 1 ).

Histological specimens of the submandibular gland showed that the pyramidal glandular cells of the acini had a prominent basophilia of the cytoplasm and the basally located nucleus. Numerous large homogeneous granules with products of secretion were located in the apical pole and in central part of the cells.

During the study, after exposure of $1 \%$ methacrylate for 14 days, the outer and inner diameter of the acini were $37.33 \pm 2.96 \mu \mathrm{m}$ and $8.83 \pm 0.72 \mu \mathrm{m}$, respectively, which did not differ significantly from the same parameters of the control group of rats. The height of the acini epithelial cells of the submandibular glands lobules was $17.73 \pm 1.11$ $\mu \mathrm{m}$, which was by $25.04 \%$ significantly more than its value in the control group of animals. On day 14 of the study in 
the cytoplasm of the epithelial cells, an increased optical density was observed due to increase in secretory granules that occupied the cytoplasm of the cells (Fig. 1).

On day 30 of the experiment morphometric study has established that the diameter of the outer acini of the lobules of the rats' submandibular glands was $28.99 \pm 2.14 \mu \mathrm{m}$ that was significantly lower by $22.34 \%$ than the values on day 14 of the experiment and by $20.07 \%$ lower than the value in the control group.

No significant difference in the values of the diameter of the lumen compared to previous time period of the experiment was detected; however, they were by 20.07 $\%$ lower than the values in the control group, accounting for $7,89 \pm 0,82 \mu \mathrm{m}$. The height of the epithelial cells was $10.72 \pm 0.98 \mu \mathrm{m}$ that was significantly lower by $39.54 \%$ than the value on day 14 of the experiment after the effect of $1 \%$ methacrylate and by $24.40 \%$ than the mean values in the control group of rats.

The cytoplasm of the acinar epithelial cells was heterogeneous; secretory granules of different optical density were detected that was caused by the presence of protein and carbohydrate components in them. Thickening of the interstitial connective tissue and prominent intercellular fissures were visualized. The lumens of the blood vessels of the microcirculatory bed were dilated (Fig.2).

Thus, the comparison of our results with previous studies has shown that the acini of the rats' submandibular glands after exposure of $1 \%$ methacrylate had unidirectional relationship with the acini of the minor submandibular salivary glands, which on day 30 showed a decrease in height of the epithelial cells by $50 \%$, compared to day 14 of the experiment, and by $25.3 \%$ compared to control group of rats [7].

The height of the epithelial cells of the acini of the submandibular salivary gland decreased by $39.54 \%$, compared to the previous time period of the experiment, and by $24.40 \%$ compared to the control group of rats that was primarily caused by location of the minor salivary glands in the thickness of the lamina propria of the hard palate mucosa and the direct influence of the denture base monomer on them.

The study of the structure of the lobules of the rats' submandibular salivary glands in stimulation of the sympathetic and parasympathetic units has revealed adrenaline-related significant enlargement of the outer diameter by $12.65 \%$, an increase in the height of epithelial cells by $14.86 \%$ with a decrease in the diameter of the lumen of the acini of the lobules of the rats' submandibular glands that is a morphological evidence of increased secretory activity of seromucosal cells with predominance of carbohydrate content in the secretory granules of the acini in response to stimulation [21, 22]. Acetylcholine injection lead to the significant decrease of the outer diameter by $6.07 \%$, a significant decrease of diameter of the lumen by $58.89 \%$, an increase of height of the epithelial cells, compared to the control group during morphometric study. Consequently, it has been found that stimulation of cholinoreceptors led to hypersalivation with increasing functional activity of all secretory components and was manifested by the decrease in the absolute size of the granules in the mucosa secreting cells and their tinctorial properties. This changes correspond to the changes after the effect of methacrylate on day 14 of the experiment with an increase in secretory activity in response to the effect of exogenous factor, caused by compensatory mechanisms to the impact of the stimulus, with hypersalivation, unlike a single action and response of the parenchyma to stimulation of cholino- and adrenoreceptors. Subsequently, the effect of methacrylate leads to a decrease in secretory activity due to the depletion of cells of the acini of the lobules of the submandibular glands $[23,24,25]$.

It is very interesting to analyze the functional activity of the acini and their structural changes in stimulation of the rats' salivary glands by platyphyllin and proserin [26, $27,28]$. No significant changes $(p<0,05)$ in the value of the height of the epithelial cells have been noted after their impact, compared to controls, in contrast to the effect of methacrylate. However, the value of the lumen diameter in stimulation with platyphyllin decreased by $45.2 \%$, with no significant changes in values in control group after influence of proserin. After the effect of $1 \%$ methacrylate, the values of the lumen diameter were by $20.07 \%$ lower, compared to the values in controls. The changes were caused by the warming of the interstitium after influence of platyphyllin, due to the stimulation of cholinoreceptors of parasympathetic postganglionic fibers and increase in the transport of juxtacellular fluid, which is the morphological feature of increased functional activity of seromucous cells of the acini in response to stimulation during the experiment. The established increase of the secretory activity of the epithelial cells in response to methacrylate occurs only in the middle of the experiment due to the enhanced activity of the secretory apparatus of cells and, as a consequence, increased the number of secretory granules (Fig. 1).

The ethanol influence on the acini of the rats' submandibular glands in the middle of the experiment showed a decrease of the outer and inner diameters by $7.57 \%$ and $14.61 \%$, respectively; the height of the epithelial cells decrease by $6.11 \%$ compared to control with a tendency to decrease throughout the experiment, due to inhibition of secretion, in contrast to the effect of methacrylate, where the height of the epithelial cells significantly increased on day 14 of the experiment by $25.04 \%$, due to the compensatory increase in secretion. At the end of the experiment, the height of the epithelial cells decreased by $24.40 \%$ compared to the control group of animals, which indicates the depletion of secreting cells due to the permanent toxic effect of methacrylate; a decrease by $21.44 \%$ of the height of the epithelial cells induced by ethanol, compared to the control group, occurs due to dystrophic changes and restructuring of the secretory apparatus to carbohydrate synthesis $[29,30]$.

\section{CONCLUSIONS}

$1 \%$ methacrylate influence on the rats' submandibular salivary glands causes the increase of secretory activity of 
glandular cells of the acini on day 14 of the experiment. It is confirmed by an increase of the height of the epithelial cells by $25.04 \%$ and is a compensatory reaction of the salivary glands to the action of methacrylate. This is accompanied by hypersalivation, which subsequently leads to complete depletion of the secretory apparatus of the seromucous cells of the acini and is confirmed by a decrease in the outer and inner diameters with decrease in height of epithelial cells of the acini of the submandibular salivary glands by $24.40 \%$, due to prolonged effect of $1 \%$ methacrylate on the oral cavity mucosa.

\section{REFERENCES}

1. Kharchenko 0.A., Balan H.M., Kharchenko T.F. Adverse effects of polymeric materials used in medical practice (modern aspects). Modern Problems of Toxicology. 2012; 1: 6-15.

2. Levytskyi V.le., Khromjiak U.V. Development of high-strength highadhesive methyl methacrylate - copolymer compositions. Bulletin of National University «Lviv politekhnika». 2012; 726:. 427-433.

3. Khromjiak U.V., Levytskyi V.le., Suberliak O.V. Synthesis and properties of adhesive polymer-methyl methacrylate compositions. Bulletin of the Kiev National University of Technology and Design. 2010; 4: 109-115.

4. Hasiuk P.A. Clinical features of prosthetics of patients with prosthetic stomatopathy. Bulletin of Problems of Biology and Medicine. 2013;2( 2): 227-29.

5. Senchakovych Yu.V., Yeroshenko G.A. Morphometric characteristics of rat microcirculatory segments in experimental hyposalivation. Bulletin of Problems of Biology and Medicine. 2014; 3 (112): 275-78.

6. Rêgo M.J.B.M.,CavalacantiC.L.B., Beltrão E.I.I., Sobral A.V. Histochemical localization of carbohydrates in morphological stages of developing human minor salivary glands: a comparative study with cytoskeletal markers. Int J Morphol. 2011; 29(2):604-613.

7. Yeroshenko G.A., Senchakovich Yu.V., Yeroshenko A.I. Methakrylateinduced changes in metric parameters of rat palatine glands. European International Journal of Science and Technology.2015; 4(3): 132-35.

8. Shevchenko K.V., Yeroshenko G.A., Kramarenko R.D., et al. Modern view about the structural and functional organization of the salivary glands. Bulletin of Problems of Biology and Medicine. 2018; 3(145): 50-8.

9. Kuzniak N.B., Dmytrenko R.R., Fedoniuk L.Ya., et al. Development of the inner nasal cavity in animals in phylo- and ontogenesis: functional anatomic significance in the development period. Wiad. Lek. 2019; 3: 432-435.

10. Denysov A.B. Saliva and salivary glands. Russian Academy of the Medical Sciences: Moscow, Yzd-vo RAMN. 2009; 470 s.

11. Topol I., Kamyshny A. Study of expression of TLR2, TLR4 and transckription factor NF-kB structures of galt of rats in the conditions of the chronic social stress and modulation of structure of intestinal microflora. Georgian Med News. 2013; (225): 115-22.

12. Hnatiuk M.S., Hasiuk P.A. Histochemical characteristics of the structure of the acinar department of the large salivary glands of man. Medical Chemistry. 2012; 14(1): 118-120.

13. Regional peculiarities of the distribution of innate and adaptive immune cells in different segments of the intestine as factor determining the localization of the pathological process. Zherebiatiev AS, Kamyshnyi AM. Eksp Klin Gastroenterol. 2015;(2):46-51.

14. Chen S., Gao F., Kotani A., Nagata T. Age-related changes of male mouse submandibular gland: a morphometric and radioautographic study. Cell Mol Biol (Noisy-le-grand) 1995; 41: 117-24.
15. Ellis H. Anatomy of the salivary glands. Surgery (0xford) 2012; 30: 569-572.

16. Bahriy M.M., Dibrova V.A., Popadynets O.H., Hryshchuk M.I. Methods of morphological studies. Vinnitsa: Nova knyha; 2016. 328s.

17. Yeroshenko G.A., Shepitko V.I., Yakushko 0.S., Vilkhova 0.V. A method of coloring semi-thin sections. Utility model patent № 75669 . Published. 10.12.2012. Bulletin № 23.

18. Lapach S.N., Chubenko A.V., Babich P.N. Statistical methods in biomedical research using Excel. Kiev: Morion; 2000. 320 s.

19. European convention for the protection of vertebrate animals used for experimental and other scientific purposes. Strasbourg: Council of Europe; 1986. p.53.

20. Bancroft J.D., Layton C. Theory and practice of histological techniques, 7th edition Churchill Livingstone, Edinburgh, London, Madrid, Melbourne, New York, Tokyo; 2013.

21. Klein R.M. Development, structure, and function of salivary glands Oral development and histology. 3rd ed New York: Avery, JK Thieme Publisher; 2002.

22. Amano 0., Mizobe K., Bando Y., Sakiyama K. Anatomy and histology of rodent and human major salivary glands: -overview of the Japan salivary gland society-sponsored workshop. Acta Histochem Cytochem, 2012; 45: 241-50.

23. Yeroshenko G.A., Shepitko V.I., Kostylenko Yu.P. Structural organization of the mandibular rat gland after administration of adrenaline and acetylcholine. Bulletin of Scientific Research. 2008; 3: 50-8.

24. Nelson D.A., Manhardt C., et al. Quantitative single cell analysis of cell population dynamics during submandibular salivary gland development and differentiation. Biology Open. 2; 2013; 439-447 10.1242/ bio.20134309.

25. Garrett J., Suleiman A., Anderson L., Proctor G. Secretory responses in granular ducts and acini of submandibular glands in vivo to parasympathetic or sympathetic nerve stimulation in rats. Cell and tissue research 1991; 264: 117-126.

26. Yeroshenko G.A., Shepitko V.I., Tsukanov D.V., Hnidets V.A. Morphometric characteristics of the salivary glands of rats after the administration of proserin and platyphilin. The World of Medicine and Biology. 2011; 3(30): 7-10.

27. Garrett J.R., Anderson L.C. Rat sublingual salivary glands: secretory changes on parasympathetic or sympathetic nerve stimulation and a reappraisal of the adrenergic innervation of striated ducts. Arch Oral Biol, 1991; 36: 675-83.

28. Greene E.C. Anatomy of the Rat. Anatomy of the rat. 1995.

29. Shevchenko K.V., Garets V.I., Fedonyuk L.Ya., Volkov K.S., Nesteruk C.O. Histophysiology of submandibular salivary glands end-pieces in rats with chronic ethanol intoxication. World of medicine and biology.2018; 4 (66): 231-34.

30. Shevchenko K.V., Yeroshenko G.A., Yakushko 0.S., Kazakova K.S., Kramarenko D.R. Morphometric description of the exchange segment of microvasculature of rats' salivary glands in normal conditions and chronic ethanol intoxication. Wiad. Lek. 2019; 72( 3): 323-326.

The work is a fragment of inter-department al scientific research work "Experimental morphological study of the effect of cryopreserved cord blood products and embriofetoplacental complex (EFPC), diphereline, ethanol and $1 \%$ methacrylate on the morphofunctional condition of several internal organs" (state registration number 0119U102925). 


\section{ORCID and contributorship:}

Galyna A. Yeroshenko - 0000-0003-4279-485X A,D,E

Larysa Ya. Fedoniuk - 0000-0003-4910-6888 ${ }^{E, F}$

Konstantyn V. Shevchenko - 0000-0003-1665-3236 ${ }^{B}$

Denys R. Kramarenko - 0000-0001-9837-8762 ${ }^{D}$

Anastasiia I. Yachmin - 0000-0002-1829-7610 C,F

Olena V. Vilkhova - 0000-0002-3371-9930 C

Tetiana A. Skotarenko - 0000-0002-3467-8990 ${ }^{B}$

\section{Conflicts of interest:}

Authors declare no conflict of interest.

\section{CORRESPONDING AUTHOR}

Larysa Ya. Fedoniuk

Medical Biology Department,

I. Horbachevsky Ternopil National Medical University,

Valova street, 9, Ternopil, 46000, Ukraine

tel: +380673999143

e-mail: Fedonyuk22Larisa@gmail.com

Received: 18.02.2020

Accepted: 10.06 .2020

A - Work concept and design, B - Data collection and analysis, C - Responsibility for statistical analysis,

D-Writing the article, $\mathbf{E}$ - Critical review, $\mathbf{F}$ - Final approval of the article 